\title{
Bacteriological Spectrum and their Anti-Microbial Susceptibility Pattern in Diabetic Ulcer Patients Attending the Tertiary Care Hospital to Facilitate the Reduction in Morbidity and Amputation
}

\author{
Aneeta Alexis* and M. Sakthivennila \\ Department of Microbiology, Kanyakumari Govt Medical College, Asaripallam-629201, \\ Kanyakumari District, India \\ *Corresponding author
}

\section{A B S T R A C T}

Diabetes Mellitus is a group of metabolic disorder in which there is increase in blood glucose over a prolonged period. Out of the complications, Diabetic foot ulcer (DFU) is a major medical, social, and economic problems and is the leading cause of hospitalization for patients with diabetes. Escherichia coli, Proteus spp., Pseudomonas spp., Staphylococcus aureus and Enterococcus spp., are reported as frequent organism isolated from cases of diabetic foot infections. Proper management of these infections requires appropriate antibiotic selection following antimicrobial susceptibility results. This study aims at evaluation of the clinical and the Microbial characteristics of diabetic foot infection in the patients in and around Kanyakumari, Tamilnadu and the antimicrobial susceptibility

\section{Keywords}

Tertiary care hospital, Diabetic ulcer,

Bacteriological

Spectrum

Article Info

Accepted:

12 April 2018

Available Online:

10 May 2018 pattern of the isolated bacteria. Prevalent study to analyze the type of bacteria causing wound infection in Diabetic patients for a period of 2 months. 98 patients suffered from diabetic foot ulcer were enrolled in this study. The antimicrobial susceptibility of micro organisms is done by KirbyBauer disc diffusion method with the necessary discs as recommended by Central Laboratory Standard Institute. Out of 102 isolates, 99 are found to have growth. Aerobic Gram-negative bacteria were the most commonly isolated pathogens and accounted for $94 \%$ of all isolates and gram positive which accounts for $6 \%$. The most common individual isolates was Klebsiella pneumoniae (47\%) followed by Pseudomonas aeruginosa (19\%), Proteus mirabilis (15\%), Citrobacter sp. (6\%), Escherichia coli (6\%), Acinetobacter sp. (2\%), Staphylococcus aureus (3\%). Klebsiella pneumoniae was more sensitive to Imipenem (89.58\%) Klebsiella pneumoniae is found to be mostly sensitive to antimicrobials such as Imipenem (90\%) cefoperazone sulbactum(79\%), Piperacillin tazobactum $(63 \%)$, chloramphenicol (60\%). The organism was resistant to most of Cepalosporins, Fluoroquinolones and Co trimoxazole. proteus isolates are more sensitive to Imipenem and Cefoperazone sulbactum. It is followed by Piperacillin tazobactum (93\%). Proteus is resistant to Levofloxacin (87\%) and Cotrimoxazole(87\%). Pseudomonas shows highest sensitivity to antimicrobials like Imipenem (89\%), followed by Piperacillin tazobactum (79\%), Cefoperazonesulbactum (68\%), Tobaramycin (60\%) and resistance to antimicrobials such as Levofloxacin (89\%), Ofloxacin (84\%), Gentamicin (74\%). There is high prevalence of ESBL producers and MRSA which threatens us towards a more dreadful post antibiotic era. Application of molecular techniques may lead to more accurate microbial characterizations and targeted antibiotic therapy which is still farfetched in many tertiary care centers too. Therefore, it is necessary to evaluate the different microorganisms infecting the wound on a routine basis and to know the antibiotic susceptibility patterns of the isolates from the infected wound in patients with diabetic foot lesions which ultimately reduces the rate of amputations.

\section{Introduction}

Diabetes Mellitus is a group of metabolic disorder in which there is increase in blood glucose over a prolonged period. According to WHO" Diabetes mellitus is a chronic disease caused by inherited and/or acquired deficiency in production of insulin by the pancreas, or by 
the ineffectiveness of the insulin produced. Such a deficiency results in increased concentrations of glucose in the blood, which in turn damage many of the body's systems, in particular the blood vessels and nerve". (1)

There are 422 million people in the world living with diabetes as on April 2017. The global prevalence of diabetes has grown from $4.7 \%$ in 1980 to $8.5 \%$ in 2014 . Whereas in India it is estimated that currently there are 69.1 million people are suffering from the disease with an overall prevalence is about $9.3 \%$. The prevalence of diabetes in Tamilnadu is $10.4 \%$ (2). Much of this increase will occur due to increased age of the population, unhealthy diets, obesity and sedentary lifestyles. Every year it is estimated that 2.2 million people in the world die due to the diabetes or its related causes (4).

Out of the complications, Diabetic foot ulcer (DFU) is a major medical, social, and economic problems and is the leading cause of hospitalization for patients with diabetes. In addition it also caused increased mortality (3). Diabetic people have $25 \%$ chances of developing foot ulcer. The annual cost of diabetes is tremendously expensive; it was $\$ 245$ billion in 2012 (4).Wound infections complicates the ulcer. It develops due to improper foot care [5]. It usually begins superficially and ultimately leads to dreaded complications such as gangrene and amputations [6]. Escherichia coli, Proteus spp., Pseudomonas spp., Staphylococcus aureus and Enterococcus spp., are reported as frequent organism isolated from cases of diabetic foot infections [7]. They end up with amputation if not treated on time. At least one in five results in a lower extremity amputation due to delayed antibiotic therapy. Rates of amputation in patients diagnosed with diabetes are typically 10 to 20 times those of nondiabetic populations.
Amputation occurs even more when foot ulcer and foot ischemia coexist. Other risk factors include age, peripheral vascular disease, low transcutaneous oxygen, smoking and poor glycemic control. The main pathophysiology of foot infection with diabetics is quite complex which is due to host-related disturbances and pathogen related factors. Host related disturbances include immunopathy, arteriopathy, neuropathy, nephropathy etc. And the pathogen related factors includes virulence, antibioticresistance and microbial load (8)

Deformed foot develops an ulcer when trauma disrupts the protective skin envelope. The underlying subcutaneous tissues quickly become colonized with bacteria which lead to infection. Infection usually begins as local response manifested by classic signs and symptoms of inflammation. If not controlled, infection spreads to deeper tissues. In some, especially with peripheral neuropathy or vasculopathy, these symptoms and signs may be diminished leading to advocate the infection by the secondary findings like foul odor, friable or discolored granulation tissue. The deep dermal tissues of all chronic wounds harbour microorganisms, however the precise interaction between microbes in the wounds and impaired healing is unknown. With regard to antibiotic therapy, there is a lack of evidence concerning its effectiveness, optimal regimens or clinical indications for treatment.

Despite this lack of evidence, antibiotics are frequently a feature of the management of chronic wounds and these patients receive significantly more antibiotic prescriptions (both systemic and topical) than age and sexmatched patients. Current guidelines for antibiotics prescribing for such wounds are often based on expert opinion rather than scientific fact and may present difficulties in interpretation and implementation to the clinician. Although the increasing prevalence 
of antibiotic resistance is widely recognized, the relationships between antibiotic resistance, chronic wound microbiology and rationales for antibiotic therapy have yet to be determined.

Proper management of these infections requires appropriate antibiotic selection following antimicrobial susceptibility results. Infection with multidrug resistant organisms (MDROs) may increase the duration of hospital stay and may cause additional morbidity and mortality. Although increasing antimicrobial resistance is a pertinent problem in India, there is a paucity for data on the frequency of multidrug resistant organisms (MDROs) infection and outcome of such infection among DFU. Hence there arises the need to evaluate the infecting microorganisms on a routine basis.

This study is done in the purpose to evaluate the clinical and the Microbial characteristics of diabetic foot infection in the patients in and around Kanyakumari, Tamilnadu. Thus it act as proactive approach to report susceptibility pattern of organisms and will help the clinician use appropriate antibiotics.

The main aim and objectives for this study includes to analyse the types of Bacteria causing wound infections in Diabetic patients attending our patients. To know the antimicrobial susceptibility pattern of the commonly isolated aerobic Bacteria. Also to detect the extended spectrum Beta-lactamase producers among Gram Negative Bacteria. To detect the Methicillin resistance in Staphylococcus aureus and Coagulase negative Staphylococci (CONS). To formulate and implement an emperical hospital antimicrobial policy for patients with diabetic ulcers. And to guide the clinician with early bacteriological diagnosis and appropriate antimicrobial treatment of choice which can salvage the organ from amputation and at large reduce the morbidity and mortality.

\section{Materials and Methods}

\section{Study design}

This prevalence study is to analyse the type of bacteria causing wound infection in Diabetic patients attending Kanyakumari Government Medical College Hospital, Nagercoil, Tamil Nadu. The study also aims at the antimicrobial susceptibility pattern of the isolated bacteria.

\section{Source of sample and questionnaire}

The duration of the study is for two months during the period from June 2017 to July 2017. A total of 98 patients suffered from diabetic foot ulcer were enrolled in this study. Prior consent is obtained from the patients. Information regarding patients' demographic and clinical features such as Name, Age, Sex, Type of Diabetics, Duration since first diagnosis, Duration of stay in the hospital, Glycemic control during treatment, Size of ulcer, Family history, awareness about complication, personal history(smoking, alcoholic), History of hypertension, neuropathy, trauma and other peripheral vascular diseases. Clinical outcomes are noted for each patient. Clinical assessment of signs and symptoms (swelling, exudates, surrounding cellulitis, odour, tissue necrosis, crepitation, pyrexia) is made. Ulcer size is determined by multiplying the longest and widest diameter.

\section{Microbiological methods used}

Wound specimens such as pus, and wound exudates are collected from the patient. For ulcer, before sampling the wound was debrided with a sterile scalpel and rinsed with sterile normal saline. Specimens are obtained by deep swabs or aspirating the pus from abscesses. When obtaining a specimen for culture and sensitivity testing, it is a key to collect material that is not contaminated with 
colonizing flora, but contains true pathogens. Since prior antibiotic therapy can cause falsenegative cultures, it is best if specimens can be obtained before such therapy is begun. The specimen is placed in an appropriate sterile transport container and rapidly sent to the microbiological laboratory for bacterial isolation. Each specimen is streak inoculated and incubated aerobically at $37^{\circ} \mathrm{c}$ overnight. The organisms are isolated in pure culture on the solid media.

\section{Antimicrobial susceptibility testing}

The antimicrobial susceptibility of microorganisms is done by Kirby-Bauer disc diffusion method with the necessary discs as recommended by Central Laboratory Standard Institute (CLSI) (48). 4to 5 similar looking colonies are picked and inoculated into peptone water. The density of the broth is adjusted to by comparing its turbidity with that of $0.5 \mathrm{Mc}$ Farland opacity standard tube. It is inoculated on the Muller Hintoin Agar medium with the antibiotic discs and left overnight to obtain semi confluent growth. The zone of inhibition and sensitivity are measured after 18hours and noted down. Gram negative bacteria are also tested for extended spectrum Beta lactamases (ESBL) production by screening test as recommended by Central Laboratory Standard Institute (CLSI). ESBL production can be tested by screening methods and confirmatory texts. In this study screening for ESBL production is done by using cefpodoxime (mg) discs along with other $3^{\text {rd }}$ generation cephalosporin discs (18). And the Staphylococcal species are tested for Methicillin Resistance (MRSA and MR-CONS) by using cefoxitin disc along with the recommended drugs for Staphylococcus.

\section{Inclusion criteria}

Type 2 diabetes mellitus Patients with chronic ulcers are included.

\section{Exclusion criteria}

Patients who has been started with antibiotic treatment for diabetic foot ulcer are excluded.

\section{Results and Discussion}

\section{Distribution according to age and sex}

A total of 102 patients who have diabetic foot ulcer are included in this study. Out of 102 patients, 76 are males $(75 \%)$ and 26 are female $(25 \%)$.

The mean average age of the patients is 59.2. Approximate ratio of male and female is $3: 1$. The age of patient ranges between 30 and 80 . Here maximum no. of affected patients lies between of age group 51-60 of both male and female equally.

It is followed by the age group 61-70(22\%) with males $73 \%$ and females $27 \%$, 71$80(18 \%)$ with male $83 \%$ and female $18 \%$, $<40(12 \%)$ with males $83 \%$ and females $12 \%$. The least affected group is $>81(2 \%)$ in which only males are affected. It is summarized in table 1 and 2 . Of the 102 diabetic patients, $61(60 \%)$ patients had random blood sugar more than $200 \mathrm{mg} / \mathrm{dL}$.

\section{Microbes isolated from culture}

Out of 102 isolates, 99 are found to have growth. Aerobic Gram-negative bacteria were the most commonly isolated pathogens and accounted for $94 \%$ of all isolates and gram positive which accounts for $6 \%$.

The most common individual isolates was Klebsiella pneumoniae (47\%). It is followed by Pseudomonas aeruginosa (19\%), Proteus mirabilis (15\%), Citrobacter sp. (6\%), Escherichia coli (6\%), Acinetobacter sp. (2\%), Staphylococcus aureus (3\%). It is summarized in table 3. 


\section{Antimicrobial susceptibility}

\section{Klebsiella pneumoniae $(\mathrm{N}=48)$}

Klebsiella pneumonia is found to be mostly sensitive to antimicrobials such as Imipenem (90\%) cefoperazone sulbactum (79\%), Piperacillin tazobactum (63\%), chloramphenicol (60\%), and sensitivity to Cefepime was only $29 \%$. The organism was resisitant to most of Cepalosporins, Fluoroquinolones and Co trimoxazole; the incidence of resistance is as follows; Cefuroxime (92\%), Ampicillin sulbactum (90\%), Amoxicillin clavulanic acid (90\%), Cefpodoxime (90\%). It is summarized in table 4.

\section{Proteus mirabilis $(\mathrm{N}=15)$}

All the isolates are more sensitive to Imipenem and Cefoperazone sulbactum. It is followed by Piperacillin tazobactum (93\%). Proteus is resistant to Levofloxacin (87\%) and Cotrimoxazole $(87 \%)$. It is summarized in table 5.

\section{Pseudomonas aeruginosa $(\mathrm{N}=19)$}

The organism shows highest sensitivity to antimicrobials like Imipenem (89\%), followed by Piperacillin tazobactum (79\%), Cefoperazone-sulbactum (68\%), Tobaramycin $(60 \%)$ and resistance to antimicrobials such as Levofloxacin (89\%), Ofloxacin (84\%), Gentamicin (74\%). It is summarized in table 6.

\section{Citrobacter spps. $(\mathrm{N}=\mathbf{6})$}

All the isolates are found to be mostly sensitive to antimicrobials like Cefepime, Piperacillin tazobactum, Cefoperazone sulbactum. All are found resistant to Cefuroxime, Gentamicin, Levofloxacin. It is summarized in table 7 .

\section{Escherichia coli $(\mathrm{N}=6)$}

Escherichia coli is more sensitive to antimicrobials like Imipenem, Cefoperazone sulbactum. They all are found to be resistant to antimicrobials like Cotrimaxazole and Cephalosporins. It is summarized in table 8 .

\section{Staphylococcus aureus $(\mathbf{N}=3)$}

Highest sensitivity is found to Vancomycin. The most resistant antibiotics are Cotrimoxazole, Cipro/levo/of, Gentamicin, Amoxicillin clavulanic acid. Staphylococcus which are isolated are resistant to Penicillin (67\%). They are also found to have Methicillin resistance (resistant to Cefoxitin $67 \%$ ). It is summarized in table 8 .

A very few Acinetobacter species are also isolated. They are found to be resistant to all the antimicrobial discs tested.

Diabetes is a serious systemic disorder in which there exists high blood glucose levels. Diabetic wounds are injuries to the body tissues caused by physical trauma and proceed to deeper layers if untreated due to the high sugar level in the blood. Physicians have an important role in the prevention, early diagnosis and management of diabetic foot complications. Management however entails an extensive knowledge of the major risk factors for amputation and preventive maintenance. In the present study, we found that elderly patients of mean average age 59.2 constituted the majority of patients with foot infections. These findings are almost similar to other studies conducted where the mean age group affected was 58 years $(20,21)$. This may be explained by the fact that foot lesions occur commonly among patients with diabetes, particularly the elderly and those with sensory neuropathy. Previous studies have shown that the susceptibility to foot infections is greater in male patients than in 
female patients (22). The present study also showed the same result with male preponderance (69 males and 32 females). Male preponderance in the present study could be explained on the basis that the males spend more time working outdoors, exposing their foot to more traumas $(23,24)$. In the present study, we found that the majority of lesions were located on the toes and plantar region, this is in accordance with the results of some studies (25).

In the study we collected 98 samples which had shown bacterial growth and 3 samples $(2.94 \%)$ did not show any bacterial growth. Similar no growth samples has also been observed in other studies $(29,30)$. Probably the cultures could have been negative because either the wounds were not infected at the time of the study or the causative agents were anaerobes. However, available evidence does not support the use of antimicrobials in uninfected diabetic foot ulcers (31). Most of the samples that were processed were found to contain Gram-negative bacteria 94.93\%. Some studies also found that Gram-negative bacteria (Proteus species, E. coli, and Pseudomonas aeruginosa) were predominant bacteria [26, 27]. Increase in ratio of Gram-negative in this study may be due to immunocompromised diabetes states of the patients who were highly susceptible to hospital-acquired infections, either by colonization with environmental strains or followed invasive surgical procedures, and exert their pathogenic effects by producing endotoxin (28) (Fig. 1).

We found that Klebsiella pneumoniae was the most predominant pathogen isolated from the patients followed by Pseudomonas aeruginosa, Proteus mirabilis, Citrobacter, Escherichia coli and Staphylococcus aureus. Whereas some studies stated that Pseudomonas aeruginosa was the most frequently one $(26,27)$.

Source of infection, use of antibiotic drug for treatment, sample collection method, geographical variation, and type and severity of the infections can influence the diversity of pathogens in different geographical areas. All the isolates were tested for their antibiotic sensitivity and resistance pattern.

Table.1 Distribution according to age and sex

\begin{tabular}{|l|l|l|l|l|l|l|l|}
\hline Age groups & Male & \multicolumn{3}{|l|}{ Female } & \multicolumn{2}{l|}{ Total } \\
\hline & & & & & & \\
\hline & $\mathrm{N}=102)$ & \\
\hline & & $\%$ & $\mathrm{~N}$ & $\%$ & $\mathrm{~N}$ & $\%$ \\
\hline$<40$ & 10 & 83 & 2 & 17 & 12 & 12 \\
\hline $41-50$ & 9 & 56 & 7 & 44 & 16 & 16 \\
\hline $51-60$ & 24 & 75 & 8 & 25 & 32 & 31 \\
\hline $61-70$ & 16 & 73 & 6 & 27 & 22 & 21 \\
\hline $71-80$ & 15 & 83 & 3 & 17 & 18 & 18 \\
\hline$>81$ & 2 & 100 & 0 & 0 & 2 & 2 \\
\hline
\end{tabular}


Int.J.Curr.Microbiol.App.Sci (2018) 7(5): 1465-1479

Table.2 Distribution according to age and sex

\begin{tabular}{|l|l|l|l|l|}
\hline \multirow{2}{*}{$\mathrm{N}=102$} & \multicolumn{2}{|l|}{ MALE } & \multicolumn{2}{|l|}{ FEMALE } \\
\hline & $\mathrm{N}$ & $\%$ & $\mathrm{~N}$ & $\%$ \\
\hline & 76 & 75 & 26 & 25 \\
\hline OVERALL & & & & \\
\hline
\end{tabular}

Table.3 Antimicrobial susceptibility of Klebsiella pneumoniae (N=48)

\begin{tabular}{|c|c|c|}
\hline Name & Sens $\%$ & Res \\
\hline & & $\%$ \\
\hline Gentamicin & 23 & 77 \\
\hline Amikacin & 40 & 60 \\
\hline Cefuroxime & 8 & 92 \\
\hline Ceftriaxone & 23 & 77 \\
\hline Cefepime & 29 & 71 \\
\hline Cefpodoxime & 10 & 90 \\
\hline Cefoperazone & 79 & 21 \\
\hline \multicolumn{3}{|l|}{ sulbactum } \\
\hline Ciprofloxacin & 15 & 85 \\
\hline Levofloxacin & 21 & 79 \\
\hline Cotrimoxazole & 25 & 75 \\
\hline Chloramphenicol & 60 & 40 \\
\hline Imipenem & 90 & 10 \\
\hline Ampicillin & 10 & 90 \\
\hline \multicolumn{3}{|l|}{ sulbactum } \\
\hline Amoxicillin & 10 & 90 \\
\hline \multicolumn{3}{|l|}{ clavulanicacid } \\
\hline Piperacillin & 63 & 38 \\
\hline tazobactum & & \\
\hline
\end{tabular}


Table.4 Antimicrobial susceptibility of Proteus mirabilis $(\mathrm{N}=15)$

\begin{tabular}{|l|l|l|}
\hline Name & Sens \% & Res \\
\hline Gentamicin & & $\%$ \\
\hline Amikacin & 40 & 60 \\
\hline Cefuroxime & 40 & 60 \\
\hline Ceftriaxone & 27 & 73 \\
\hline Cefepime & 40 & 60 \\
\hline Cefpodoxime & 60 & 40 \\
\hline Cefoperazone & 20 & 80 \\
\hline sulbactum & 100 & 0 \\
\hline Ciprofloxacin & 20 & 80 \\
\hline Levofloxacin & 13 & 87 \\
\hline Cotrimoxazole & 13 & 87 \\
\hline Chloramphenicol & 53 & 47 \\
\hline Imipenem & 100 & 0 \\
\hline Ampicillin & & \\
\hline sulbactum & 27 & 73 \\
\hline Amoxicillin & & \\
\hline clavulanicacid & 27 & 73 \\
\hline Piperacillin & & \\
\hline tazobactum & 93 & 7 \\
\hline
\end{tabular}

Table.5 Antimicrobial susceptibility of Pseudomonas aeruginosa $(\mathrm{N}=19)$

\begin{tabular}{|l|l|l|}
\hline Name & Sens $\%$ & Res \% \\
\hline Gentamicin & 26 & 74 \\
\hline Amikacin & 53 & 47 \\
\hline Ceftazidime & 42 & 58 \\
\hline Cefepime & 58 & 42 \\
\hline Cefoperazone- & 68 & 32 \\
\hline sulbactum & & \\
\hline Ciprofloxacin & 58 & 42 \\
\hline Levofloxacin & 11 & 89 \\
\hline Ofloxacin & 16 & 84 \\
\hline Imipenem & 89 & 11 \\
\hline Tobaramycin & 60 & 40 \\
\hline Piperacillin & 79 & 21 \\
\hline tazobactum & & \\
\hline
\end{tabular}


Table.6 Antimicrobial susceptibility of Citrobacter spp $(\mathrm{N}=6)$

\begin{tabular}{|l|l|l|}
\hline Name & Sens \% & Res \\
\hline Gentamicin & 0 & $\%$ \\
\hline Amikacin & 33 & 67 \\
\hline Cefuroxime & 0 & 100 \\
\hline Ceftriaxone & 17 & 83 \\
\hline Cefepime & 100 & 0 \\
\hline Cefpodoxime & 17 & 83 \\
\hline Cefoperazone & 100 & 0 \\
\hline sulbactum & & \\
\hline Ciprofloxacin & 17 & 83 \\
\hline Levofloxacin & 0 & 100 \\
\hline Cotrimoxazole & 33 & 67 \\
\hline Chloramphenicol & 60 & 40 \\
\hline Imipenem & 67 & 34 \\
\hline Ampicillin & 17 & 83 \\
\hline sulbactum & & \\
\hline Amoxicillin & 17 & 83 \\
\hline clavulanicacid & & \\
\hline Piperacillin & 100 & 0 \\
\hline tazobactum & & \\
\hline
\end{tabular}

Table.7 Antimicrobial susceptibility of Escherichia coli $(\mathrm{N}=6)$

\begin{tabular}{|l|l|l|}
\hline Name & Sens \% & Res \\
\hline Gentamicin & 17 & 83 \\
\hline Amikacin & 33 & 67 \\
\hline Cefuroxime & 17 & 83 \\
\hline Ceftriaxone & 17 & 83 \\
\hline Cefepime & 33 & 67 \\
\hline Cefpodoxime & 0 & 100 \\
\hline Cefoperazone & 100 & 0 \\
\hline sulbactum & & \\
\hline Ciprofloxacin & 40 & 60 \\
\hline Levofloxacin & 33 & 67 \\
\hline Cotrimoxazole & 0 & 100 \\
\hline Chloramphenicol & 67 & 33 \\
\hline Imipenum & 100 & 0 \\
\hline Ampicillin & 17 & 83 \\
\hline sulbactum & & \\
\hline Amoxicillin & 17 & 83 \\
\hline clavulanicacid & & \\
\hline Piperacillin & 83 & 17 \\
\hline tazobactum & & \\
\hline
\end{tabular}


Table.8 Antimicrobial susceptibility of Staphylococcus aureus (N=3)

\begin{tabular}{|l|l|l|}
\hline Name & $\begin{array}{l}\text { Sens } \\
\%\end{array}$ & Res \% \\
\hline Erythro/azithro/clarithro & 33 & 67 \\
\hline Cefoxitin & & \\
\hline Penicillin & 33 & 67 \\
\hline Cotrimoxazole & 33 & 67 \\
\hline Linezolid & 0 & 100 \\
\hline Doxycycline & & \\
\hline Tetracycline & 33 & 67 \\
\hline Vancomycin & & \\
\hline Chloramphenicol & 67 & 33 \\
\hline Cipro/levo/ofloxacin & 67 & 33 \\
\hline Gentamicin & 100 & 0 \\
\hline Ampicillin sulbactum & 67 & 33 \\
\hline Amoxicillin clavulanicacid & 0 & 100 \\
\hline
\end{tabular}

Fig.1 Bacteriological profile of the isolates from the culture

\section{Bacteria isolated from the culture}

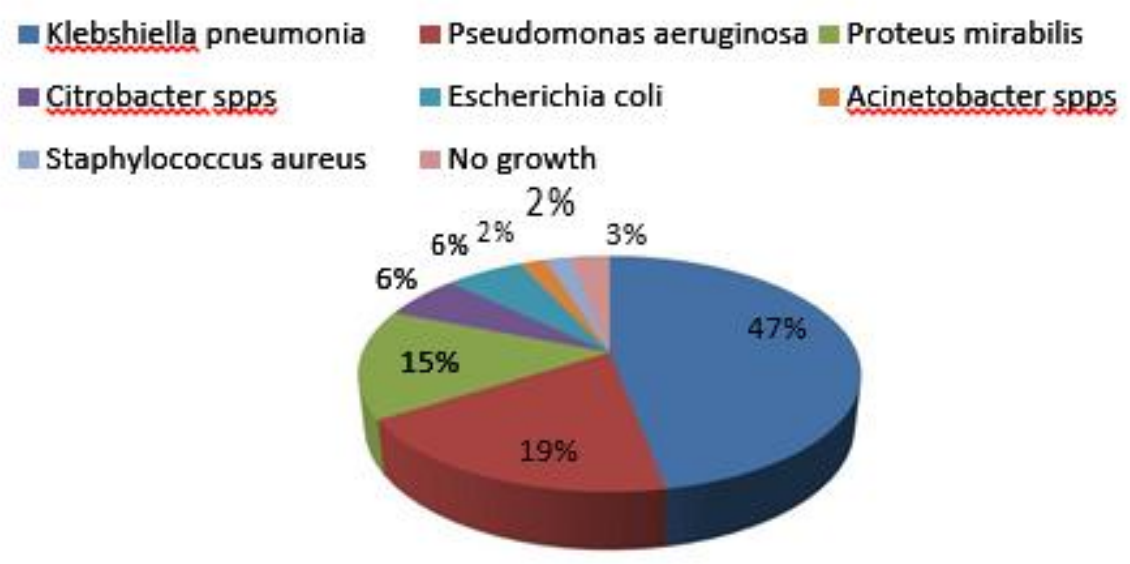




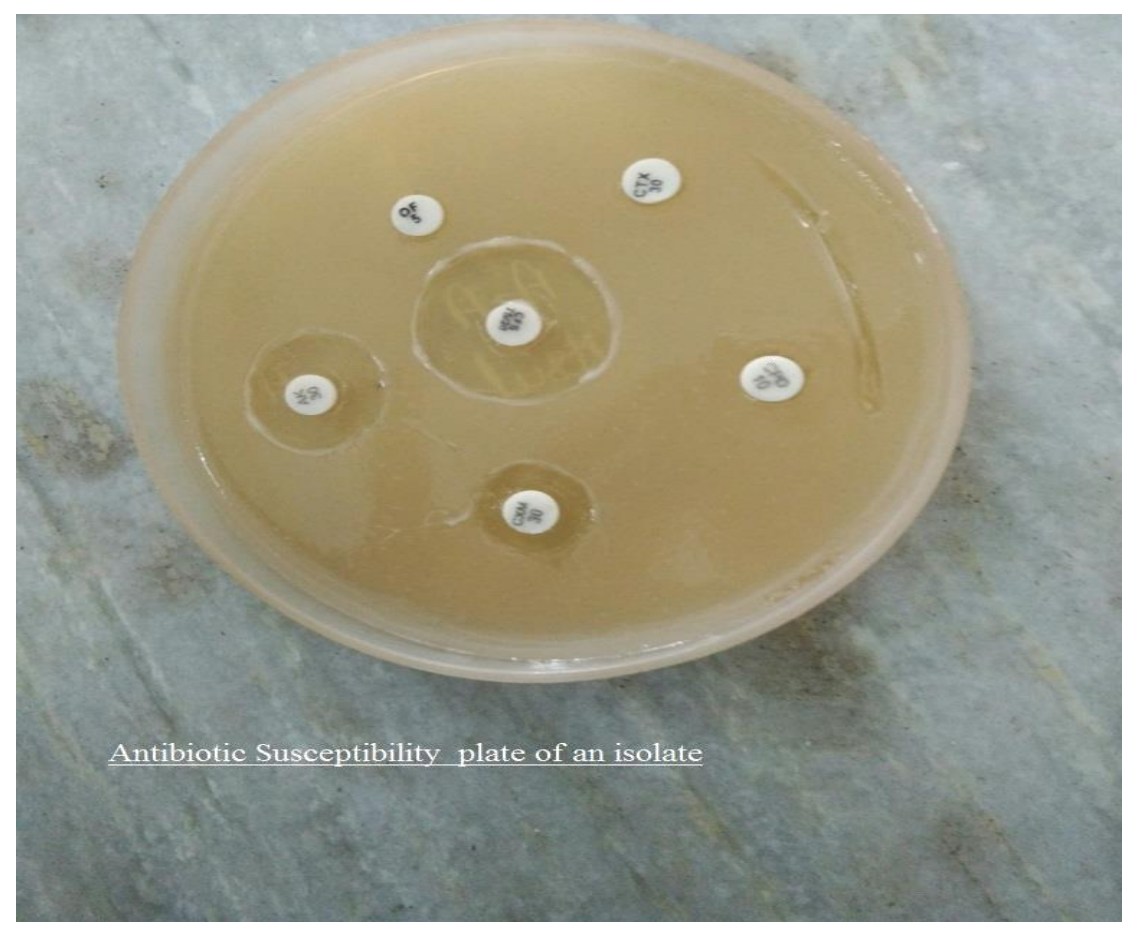

In this study, we found that Klebsiella pneumoniae was more sensitive to Imipenem $(89.58 \%)$. It is also found similar to some researches $(32,33,34,35)$. It is followed by Cefoperazone sulbactum (79.17\%). But a research shows that Klebsiella pneumoniae show considerable resistant to Cefoperazone and Cefoperazone sulbactum also (36). Our studies had shown that Klebsiella has shown resistant to Cephalosporins. It was also supported by a study (37). Resistance to Cephalosporins like Cefpodoxime suggest ESBL production

Pseudomonas aeruginosa was the second most common isolate. In this study it showed a great sensitivity to Piperacillin-tazobactam and Imipenem similar to other studies $(38,39,40)$. Fluoroquinolone like Levofloxacin are found to have resistance to Pseudomonas. Similar results were also shown by Lee YJ et al., (42). In 2011, Sivanmaliappan and Sevanan (41) reported that $66.6 \%$ of Pseudomonas aeruginosa isolates were resistant to Gentamicin. These findings are consistent with our results $(73.68 \%)$.

Next to Pseudomonas and Proteus mirabilis was the prevalent organism isolated. It is more sensitive to Imipenem. But another study also found that Proteus spp were most sensitive to Cefotaxime whereas Raja showed 98\% sensitivity to Ceftriaxone and Patel et al., showed Proteus spp were most sensitive to Cefotaxime followed by Ceftriaxone (35, 43, 44). The present study showed that $100 \%$ isolates of Proteus species were sensitive to beta lactum - lactamase inhibitor combinations such as both cefoperazone-sulbactam. It is also proved by a research (45). In our study we found that proteus mirabilis are resistant to Cotrimoxazole. It was also proved by some research (46). Fluoroquinolones are also found to be resistant. It is supported by research (47).

In case of Citrobacter, all isolates were sensitive to Cefepime, Piperacillin tazobatum, Cefoperazone sulbactum. But a research revealed that Cefoperazone sulbactum was a more sensitive inducer of ESBL than Piperacillin Tazobactum (48). The isolates were found to be resistant to Antibiotics like Gentamicin, Cefuroxime and Fluoroquinolones like Levofloxacin.

With regard to Escherichia coli all the isolates were sensitive to Imipenem and Cefoperazone sulbactum and resistant to Cotrimoxazole. It 
was partly supported by Jain Manisha (49). But a research found $E$. coli to be $100 \%$ sensitive to Amikacin and Cefotaxime (50). Resistance to Cefpodoxime as shown by most of the isolated E. coli suggests ESBL production.

A Very Few Acinetobacter species were isolated. They were all found resistant to all antimicrobial discs tested.

In our study we found that Staphylococcus aureus isolated were only 3 out of 98 isolates; of which 1 was sensitive to Penicillin and 2 were resistant. This number is very low to evaluate further. However in this study it was observed that the 2 Penicillin resistant isolates were resistance to Cefoxitin (67\%) which suggest the presence of Methicillin resistant strain. Also they are susceptible to Vancomycin. According to a cross sectional study on diabetic foot lesion carried out, the drug sensitivity results indicated that Staphylococcus are susceptible to Vancomycin (51).

The increasing incidence of multidrug resistant organisms is a potential risk factor in management of diabetic foot infections which may lead to devastating complications like systemic toxicity, gangrene formation and amputation of lower extremity. The multidrug resistant organisms are frequently resistant to many other classes of antibiotics also. So it is necessary for the clinician to be completely aware of the prevalence rate of multidrug resistant organisms and their management strategies. Thus my study gives knowledge about the prevalent organisms in the hospital patients and environment. Microbial analysis can be of benefit when considered in concert with clinical observations to confirm causative organisms. The light thrown upon by this study on antimicrobial sensitivity profile can be of essential use to the clinicians for early and appropriate attack on the bacterial flora thus controlling the infection. It facilitates the clinicians about the prompt therapy and improves the clinical outcome of the patients. Also this study emphazises the need of good infection control practices which is very important in tertiary care centre with more number of patients with a persistent risk of cross infections and health care associate infections. This study further shows that a regular system of monitoring infection routes as well as dissemination of the data form a link between the management and health care provider. Thus this work helps in implementing and improving the strategies for better control of infections.

\section{Summary}

In brief, the prevalence of gram negative bacterial infection was higher in diabetic foot patients from our region. Imipenem was found to be the best drug of the choice against gram negative organisms and Vancomycin for gram positive organisms. There is high prevalence of ESBL producers and MRSA which threatens us towards a more dreadful post antibiotic era. Application of molecular techniques may lead to more accurate microbial characterizations and targeted antibiotic therapy which is still farfetched in many tertiary care centres too. Therefore, it is necessary to evaluate the different microorganisms infecting the wound on a routine basis and to know the antibiotic susceptibility patterns of the isolates from the infected wound in patients with diabetic foot lesions which ultimately reduces the rate of amputations. This knowledge is crucial for planning the treatment of these patients with the appropriate antibiotics, reducing resistance patterns, and minimizing healthcare costs. We hope the data presented on this article can assist the clinicians in determining the multidrugresistant pathogens in diabetic foot ulcers.

\section{References}

1. Global Report on World Health Day "Beat Diabetes", April 2016 in World Health Organisation.

2. Anjana RM, Pradeepa R, Deepa M, sudha V, Unnikrishnan R, Bhansali A, JoshPP, Yajnik CS,et al., Prevalence of diabetes and prediabetes (impaired fasting glucose and/ or impaired glucose tolerance)in 
urban and rural India: India DIABetes(CMR-INDIAB) study.

3. GE Reiber, EJ Boyko, DG Smith Diabetes in America, 1995. Lower extremity foot ulcers and amputations in diabetes 2nd edn. Harris MI, Cowie C, Stern MP, eds (NIH Publication No. 951468) 1995:409-27.

4. American Diabetes Association. 2013. Economic costs of diabetes in the U.S. in 2012. Diabetes Care 36.

5. SubashVijayakumar, Dheeraj Kumar Gundela, Satyadev M. Major Bacteria Isolated from Diabetic Foot Infections. International Bulletin of Drug Research, Vol.2(3), 75-80, 2012.

6. Abd Al-HameadHefni, Al-Metwally R. Ibrahim, Khaled M. Attia, Mahmoud M., Moawad, Ayman F. El-Ramah, Mohamed M. Shahin, Mahmoud Al-Molla and LotfiAbd Al-Satar. Bacteriological study of diabetic foot infection in Egypt. Journal of the Arab Society for Medical Research, Vol. 8, 26-32.2013.

7. Gadepalli R., Dhawan B., Sreenivas V., Kapil A., Ammini A.C., Chaudhry R., A. Clinicomicrobiological study of diabetic foot ulcers in an Indian tertiary care hospital. Diabetes Care, Vol 29, 1727-32, 2006.

8. Anne Spichler, Bonnie L Hurwitz, David G Armstrong and Benjamin A Lipsky. Microbiology of diabetic foot infections: from Louis Pasteur to "crime scene investigation. BMC Medicine 2015; 13:2.

9. McLennan $\mathrm{S}$ et al., Molecular aspects of wound healing, Primary intention (2006). Primary intention(2006).14(1) 8-13.

10. Turns M (2012). "The diabetic foot: an overview for community nurses". Br J Community Nurs. 17(9):422, 424-27

11. Scott, G (March-April 2013). "The diabetic foot examination: A positive step in the prevention of diabetic foot ulcers and amputation". Osteopathic Family Physician. Osteopath Fam Physician 2013; 5: 73-8.

12. Wu, S. C., Driver, V. R., Wrobel, J. S., Armstrong, D. G. (2007). "Foot ulcers in the diabetic patient, prevention and treatment". Vascular health and risk management. Vascular Health and Risk Management. 2007;3:65-76.

13. Gadepalli, R., B. Dhawan, V. Sreenivas, A. Kapil, A. C. Ammini, and R. Chaudhry, "A clinico-microbiological study of diabetic foot ulcers in an Indian tertiary care hospital," Diabetes Care, Vol 29, 1727-32, 2006.

14. Bansal E, Garg A, Bhatia S, et al., Spectrum of microbial flora in diabetic foot ulcers. Indian Journal of Pathology \& Microbiology. 2008. Indian J Pathol Microbiol 2008;51:204-8

15. Litzelman, D. K., Slemenda, C. W., Langefeld, C. D., Hays, L. M., Welch, M. A., Bild, D. E., Ford, E. S., Vinicor, F. (1993). Reduction of lower extremity clinical abnormalities in patients with non-insulin-dependent diabetes mellitus. A randomized, controlled trial. Annals of Internal Medicine. Ann Intern Med. 1993 Jul 1; 119(1): 36-41.

16. WHO-EAKO-regional strategy on protection containment of antimicrobial resistance 2010-15 WHO - regional office for SE Asia - 2010.

17. M100-S 23 Clinical laboratory Standards Institute (CLSI) Jan 2013.

18. R. S. Howell-Jones, M. J. Wilson, K. E. Hill, A. J. Howard, P. E. Price, and D. W. Thomas. A review of the microbiology, antibiotic usage and resistance in chronic skin wounds. Indian J Pathol. Microbiol 1991; 34: 81-87.

19. Study on swab culture Vs Deep culture in chronic wound injections-Dr. Selwyn J. Kumar, Dr. J.A. Jayalal, Dr. Bhagavadh, volume: 4, issues: 8, 655-659.

20. Gadepalli R., Dhawan B., Sreenivas V., Kapil A., Ammini A.C., Chaudhry R. A. Clinicomicrobiological study of diabetic foot ulcers in an Indian tertiary care hospital. Diabetes Care Vol 29, 1727-32, 2006.

21. Ramani A, Ramani R, Shivananda PG, Kundaje GN. Bacteriology of diabetic 
foot ulcers. Indian J of Pathol Microbiol. 1991; 34(2): 81-7.

22. El-Tahawy AT. Bacteriology of diabetic foot infections. Saudi Medical J 2000. Vol. 21(4): 345.

23. Ellis Simonsen SM, Van Orman ER, Hatch BE, Jones SS, Gren LH, Hegmann $\mathrm{KT}$, et al., Cellulitis incidence in a defined population. Epidemiol Infection. 2004. 134(2): 293-299.

24. Sivanmaliappan TS, Sevanan M. Antimicrobial susceptibility patterns of Pseudomonas aeruginosa from diabetes patients with foot ulcers. Int J Microbiology, 2011; 2011: 605195.

25. Donoso MTV, Rosa EG, Borges EL. Perfi 1 dos Pacientes com Pé Diabético de um Serviço Público de Saúde. J Nurs UFPE 2013. Rev Enferm UFPE. 2013 ; 7 (7): 4740-6

26. Gadepalli, R., B. Dhawan, V. Sreenivas, A. Kapil, A. C. Ammini, and R. Chaudhry, "A clinico-microbiological study of diabetic foot ulcers in an Indian tertiary care hospital," Diabetes Care. Diabetes Care. 2006 Aug;29(8):1727-32

27. Bansal E, Garg A, Bhatia S, et al., Spectrum of microbial flora in diabetic foot ulcers. Indian Journal of Pathology \& Microbiology 2008. 51(2): 204-8.

28. Hunt, J. A. (2003). Diabetic Complication. Diabetic Medicine, 9:113116.

29. El-tahawy AT. Bacteriology of diabetic foot infections. Saudi Med J. 2000; 966(January): 344-7.

30. Mohanasoundaram KM. The Microbiological Profile of Diabetic Foot Infections. J Clin Diagn Res 6(3):409411.

31. Lipsky BA, Berendt AR, Deery HG, Embil JM, Joseph WS, Karchmer AW, et al., Diagnosis and Treatment of Diabetic Foot Infections Plast Reconstr Surg. 2006; 117(SUPPLEMENT): 212S-238S.

32. El-sheikh NA, Badawi MM, Mahran MH, Abdelfattah MM. Bacteriology of Diabetic Foot Ulcer among an Egyptian Population: A Retrospective Study A
Retrospective Study. World J Med Sci. 2014; 10(4): 494-502.

33. Hena J. Vimalin. Studies on bacterial infections of diabetic foot ulcer. African J Clin Exp Microbiol 2010; 11.

34. Ratemo DNK. Antimicrobial Susceptibility Pattern of Bacterial isolates from Pus samples at Kenyatta National Hospital, Kenya. 2014;

35. Sharma VK, Khadka PB, Joshi A, Sharma $\mathrm{R}$. Common pathogens isolated in diabetic foot infection in Bir hospital. Kathmandu University Med J. 2006; 4(3): 295-301.

36. Resistance to cefoperazone-sulbactam in Klebsiella pneumoniae: evidence for enhanced resistance resulting from the coexistence of two different resistance mechanisms. Rice LB, Carias LL, Etter L, Shlaes DM.

37. Jha, P., Baral, R., and Khanal, B. (2014). International Journal of Biomedical Laboratory Science (IJBLS) 2014 Vo1. 3, No. 2:29-34.Prevalence of Uropathogens in Diabetic Patients and Their Susceptibility Pattern at a Tertiary Care Centre in Nepal-A Retrospective Stud. International Journal of Biomedical Laboratory Science, 3(2), 29 - 34.

38. Mukadam IS, Hulyalkar VS, Shubhra S. Bacteriological Analysis of Diabetic Foot infection. Bombay Hosp J. 2011; 53(4):706-11.

39. Turhan V, Mutluoglu M, Acar A, Hatipoğlu M, Önem Y, Uzun G, et al., Increasing incidence of Gram-negative organisms in bacterial agents isolated from diabetic foot ulcers. J Infect Dev Ctries. 2013; 7(10):707-12

40. Dezfulian A, Salehian MT, Amini V, Dabiri H, Azimi M, Aslani MM, et al., Bacteriological Study of Diabetic Foot Infections at an Iranian Hospital. Iran Red Crescent Med J 2011; 35: 12-3.

41. Sivanmaliappan TS, Sevanan M. Antimicrobial susceptibility patterns of Pseudomonas aeruginosa from diabetes patients with foot ulcers Int J Microbiol 2011; 2011:605195. 
42. Lee YJ, Liu HY, Lin YC, Sun KL, Chun CL, Hsueh PR. Fluoroquinolone resistance of Pseudomonas aeruginosa isolates causing nosocomial infection is correlated with levofloxacin but not ciprofloxacin use. Int $\mathbf{J}$ Antimicrob Agents 2010;35: 261-4.

43. Raja NS. Microbiology of diabetic foot infections in a teaching hospital in Malaysia: A retrospective study of 194 cases J Microbiol Immunol Infect. 2007; 40: 39-44.

44. Patil SV, Mane RR. Bacterial and clinical profile of diabetic foot ulcer using optimal culture techniques. Int J Res Med Sci 2017; 5: 496-502.

45. N Poudyal, N Gyawali, R Gurung, NR Bhattarai, R Baral, B Khanal, S Shrestha, R Amatya, and SK Bhattacharya, 2012. In vitro activity of cefoperazonesulbactam combination against gram negative bacilli. Nepal Med Coll J. 2012 Mar;14(1):5-8

46. Patrick Kwame Feglo, Stephen Yao Gbedema, Solomon Nii Armar Quay, Yaw Adu-Sarkodie, Clement OpokuOkrah. 2017. Occurrence, species distribution and antibiotic resistance of Proteus isolates: A case study at the Komfo Anokye Teaching Hospital (KATH) in Ghana. IJPSR, Vol.1(9), 2010, 347-352

47. Martínez-Martínez, L., Suárez, A. I., Carranza, R. and Perea, E. J. (1993).
Resistencia a ciprofloxacino en bacilos gramnegativos.

Aspectos edidemiológicos. Enfermedades Infecciosas y Microbiología Clínica11, 474-8.

48. Rizvi M, Fatima N, Rashid M, Shukla I, Malik A, Siddiqui S (2009) Extended spectrum AmpC and metallo-betalactamases in Serratia and Citrobacter spp. in a disc approximation assay. The Journal of Infection in Developing Countries 3 (03): 177-186.

49. Jain Manisha, Patel Mitesh H, Sood Nidhi K, Modi Dhara J, Vegad M.M. 2012. Spectrum of Microbial Flora in Diabetic Foot Ulcer and Its Antibiotic Sensitivity Pattern in Tertiary Care Hospital in Ahmedabad, Gujarat. M M Vegad Natl J Med Res. 2012; 2(3): 354-357.

50. Anandi C, Alaguraja D, Nataranjan V. 2004. Bacteriology of Diabetic Foot Lesions Indian $\mathbf{J}$ Med Microbiol. 22(3):175-8.

51. Shameem Akhter. Study of bacterial infection and antimicrobial sensitivity pattern in diabetic foot lesion. Bangladesh Soc Med Microbiol. 2012; 6(2):20-3.

52. Science (IJBLS) 2014 Vo1. 3, No. 2:2934. Prevalence of Uropathogens in Diabetic Patients and Their Susceptibility Pattern at a Tertiary Care Center in Nepal-A Retrospective Stud. International Journal of Biomedical Laboratory Science. (2), $29-34$.

\section{How to cite this article:}

Aneeta Alexis and Sakthivennila, M. 2018. Bacteriological Spectrum and their Anti-Microbial Susceptibility Pattern in Diabetic Ulcer Patients Attending the Tertiary Care Hospital to Facilitate the Reduction in Morbidity and Amputation. Int.J.Curr.Microbiol.App.Sci. 7(05): 1465-1479. doi: https://doi.org/10.20546/ijcmas.2018.705.173 